\title{
A Multi-perspective Integrated Framework of Critical Success Factors for Supporting On-line Shopping
}

\author{
M. L. R. Varela, M. F. Ferreira, G. G. Vieira, \\ Department of Production and Systems, School of \\ Engineering, University of Minho \\ Guimarães, Portugal, leonilde@dps.uminho.pt, \\ miguelfloriano@iqne-commerce.com, \\ gaspar_vieira@hotmail.com
}

\author{
V. K. Manupati, K. Manoj \\ School of Mechanical Engineering, \\ Division of Manufacturing, VIT University, \\ Vellore, Tamil Nadu, India. \\ manupativijay@gmail.com, kakarla.manoj2013@vit.ac.in
}

\begin{abstract}
E-commerce promotes economic growth by enabling online shops to compete within a global market scenario. There are critical success factors that permit to distinguish a good business on the Internet and this knowledge may allow reaching an important competitive advantage for business sustainability. As many disciplines are involved, when determining critical success factors, e-commerce requires an effective coordination and integration in a collaborative way. In e-commerce, as well as in any other ecosystem, the breaking down of some integrating elements may provoke a collapse on the whole system. The various stakeholders involved in a given business should, therefore, be involved and work together to achieve a high quality product that fully satisfies the end customer's needs and wishes. To meet the above requirement, this paper proposes a multi-perspective critical success factors (MPCSF) model for online shopping.
\end{abstract}

Keywords - E-commerce; success factors; multi-perspective model, online shopping support.

\section{INTRODUCTION}

E-commerce has emerged as an interesting alternative way of commerce, which has emphasized its relevance to the growing instrumentalization of the web and the intensification of alternative ways of creating value [1]. Essentially, ecommerce is a type of e-business involving goods, services and information in which the parties involved do not always meet physically but interact electronically. The benefit of e-commerce is of course evident. For example, the potential of placing orders, transferring sales data and inventory information, and conducting the transactions online can significantly reduce business operations cost and increase the speed of business activities.

Given the existing competitiveness in the nowadays global market context, there is an increasing need to reach the maximum number of customers within particular niche markets. E-commerce provides many opportunities for business to reach markets that have never been possible to reach before the Internet age. Therefore, e-commerce can create significant value and generate extra sales through the virtual marketplace. Although e-commerce is already being widely explored, there is still considerable margin of growth to its maturity [2]. Furthermore, there is no guarantee that companies selling their products and services through Internet channels will be successful. Many businesses have now realized that installing computer networks inside the company and creating a website may appear easy. But building a profitable business to fulfil customer's orders online is actually a lot harder. A major challenge for e-commerce success lies in the question of how to use e-commerce to help create a sustainable competitive advantage [3].

There are a vast number of studies demonstrating the successful implementation of e-commerce, in many industrial sectors [2], which led to a strong motivation for this work, in order to further the study of the critical success factors for implementing successful businesses through e-commerce from multiple perspectives.

Thus, in this paper, a study of the whole process of ecommerce, with special focus on critical success factors is presented and discussed. The paper is organized as follows. In section 2, a brief description of the market behind e-commerce is presented. In section 3 an extensive review on the state of the art is included, with the research gap identified. Section 4 proposes a multi-perspective critical success factor (MPCSF) model and discusses, in detail, each of the success factors to be considered when putting forward an on-line shop. Finally, section 5 presents some conclusions and planned future work.

\section{MARKET DESCRIPTION}

The competitive global market of today requires companies to be in all parts of the world at the same time. E-commerce is a sophisticated tool for opening new business opportunities with a considerable competitive advantage over local markets [4]. Although there is already a great adherence and growth of ecommerce, it is expected that this still has a high degree of progression.

The demand for niche markets and marketing allies could revolutionize the new e-commerce. Recent technological changes allow cementing online business by providing payment procedures in a safer way up to highly effective logistic companies. The whole process of creating online stores involves many techniques and multidisciplinary areas, requiring a synergy of skills for obtaining the desired result [5]. Thus, much attention has to be paid to a variety of subjects related with this issue, including the study of implications of e-commerce at different levels of impact, particularly in terms of human 
behaviour and preferences, as well as the analysis of alternatives for its implementation.

Understanding what drives an on-line shopper to buy online through a website, as an alternative to traditional commerce is one of the goals that distinguish a successful project, from an inconsequential attempt. A well-known challenge for a successful on-line business provider is that it needs involvement from multiple disciplinarians, such as engineering, design, computing, communications, marketing and even psychology.

Along with the increasing success of e-commerce in global markets in recent years, especially since middle 1990s, it has been recognized that e-commerce success has been hampered by a number of reasons. One of which is the lack of conceptual frameworks that can develop and provide effective success measures [6]. The work presented in this paper is motivated by this recognition and aims to contribute to the development and provision of an integrated framework to define critical success factors for online shopping. The following section will provide a comprehensive literature review on the topic.

\section{STATE OF THE ART}

E-commerce has not evolved at the same rate in quality, although there has been a rapid growth in terms of quantity. The possibility of creating an online store and start selling immediately, without huge investment cost as an obstacle, has provided many people with no relevant knowledge to invest in this area. It is easy to prove this observation by searching online stores which, for instance, simply do not allow the understanding of how one can buy a product when being faced with a confusing website that encourages the user to immediately close the web page, even before watching its contents.

Therefore, there is still much room for improvements, by applying the logic of critical success factors. Although there are some online stores performing relatively well, designing an online store without any insightful investigation of potential success factors may turn out to be hard to succeed..

There has been a considerable amount of work carried out to identify, to measure and to evaluate critical success factors in e-commerce in recent years. Those identified, measured and evaluated success factors can be classified using a number of classification schemes (see for example, [7-13]).

The mainstream on this research classified success factors into five main categories, i.e. technology acceptance factors, social factors, cognitive factors, ethical factors and environmental factors.

Firstly, technology acceptance factors are mainly focused on the websites, including website quality and website design. Majority of the work identified information quality and system quality as the two main factors to reflect website quality $[7,8]$. Some work extended the website quality to also include service quality [9]. Originally, five dimensions were defined for physical marketplace service quality: tangibles, reliability, responsiveness, assurance and empathy [14]. In e-commerce context, methods of measuring success differ from physical marketplace service. E-service quality is therefore defined as the overall customer assessment and judgment of e-service delivery in the virtual marketplace [9]. Website design factors have been diverse; they range from usability and usefulness to interactivity and explicitly [13]. Among which, usability is probably the widely discussed factor. For example, does the website have a good structured navigation system for customers to explore the website contents and easily find their desired products or services? Of course, website design and website quality are closely related to each other. Some authors have suggested that website design, fulfilment/ reliability, privacy/security and customer services are the determinants of customer judgments of quality and satisfaction, customer loyalty and attitudes towards a company's online business [15].

In terms of social factors, those on the top of the list include the sense of virtual community, and the use of social media in online shopping, for example, in the luxury online shopping [11]. Online shoppers use blogs, customer reviews etc. to help their purchase decisions. By interacting with other customers, online shoppers feel a strong sense of community and gain satisfaction from others' feedback on the products or services that an online shop provides. Some shoppers think that peercustomers' words are more trustworthy than what specialists' marketing pitches [16].

Many other authors have, however, identified trust as an ethical factor. Trust perhaps has been one of the most discussed factors and that is why it spans across both social and ethical categories $[17,18]$. No matter to which category should trust belong, the basic meanings of trust in the e-commerce context are almost the same, i.e. about practicing privacy policies, describing products and services online objectively and honestly, and maintain transparency of the online business operations [19]. Some research has even investigated the relationship between knowledge and trust and found a positive relationship between them. Therefore a suggestion is made that online retailing practice should make the public more knowledgeable e.g. about the online transaction security mechanisms in order to build up user's trust in online shopping [20].

Environmental factors to ensure e-commerce success have not been discussed as widely as the other four categories. Only recently, a research on e-commerce trends and development to enhance online customer's satisfaction in China observed three important environmental success factors: government regulations, payment systems, and logistics systems [21].

Another interesting classification of success factors is based on the process stages of online shopping. It seems that most research in the context of $\mathrm{B} 2 \mathrm{C}$ context agrees on a four-stage process model for online shopping: information, agreement, settlement, and after-sale stages [12,22]. A process model for $\mathrm{C} 2 \mathrm{C}$ e-commerce (online auction) defined the four stages as information, communication, distribution and transaction [23]. New critical success factors developed in the process models include trade safety, governance and order, reputation and scale, communication channel, information search, transaction process and copious information.

A third classification scheme is more generic, which only have two categories of success factors: customer-centric factors and website-centric factors [10]. The work based on the case of Japan finds out that customers are more concerned about the 
customer - centric factors, especially customer's education level, creativity, and net-orientation. It seems that Japanese customers do not worry about that much about e-service quality, which is a key success factor in the website-centric category.

Based on the above comprehensive review on literature, it is evident that there have been a huge number of success factors for e-commerce being defined, and that those factors are often discussed in isolation or from a particular perspective, which limits the contribution of existing work to online shop design and implementation practice. E-commerce is a complex ebusiness process, which requires knowledge from multiple disciplines to make it successful. Therefore, there is a clear need to develop a more advanced framework that can integrate critical success factors from multiple perspectives for online shopping. It is expected that such a multi-perspective integrated framework can provide effective guidance to e-commerce provider's design and implementation of successful online stores.

\section{A MULTI-PERSPECTIVE FRAMEWORK INTEGRATING E- COMMERCE SUCCESS FACTORS}

E-commerce is undoubtedly the future that most companies will have to face. However, the fact of creating an online store does not mean guaranteed success.

E-commerce presents fresh challenges that set around a multidisciplinary environment and that must be in harmony, as there are complementary aspects arising from each area, which have to be considered and integrated, as a requirement for success [24].

Just like a real physical shop, also in e-commerce it is not just the commercial part that is implied but a whole set of assumptions that must be guaranteed and controlled. The internet is a medium with its own characteristics, where every detail must be thought out carefully so that the end result is as expected.

This paper proposes a multi-perspective model for critical success factors (MPCSF), as shown in Figure 1. The success factors included in the MPCSF model have to be considered in an integrated manner when putting forward an on-line shop and corresponding website. The authors of this paper believe that all the success factors should be considered simultaneously from multiple perspectives (technological perspective such as web design usability, social perspective such as social networks, etc.), across different e-commerce life cycle stages (e.g. pre-sale, information stage and supply chain). This proposed interdisciplinary approach includes branding and marketing in Business Management discipline; communication support in Technology and Engineering discipline; and quality data processing in Science discipline. After it is combined with the classification schemes discussed earlier in Section II (i.e. customer-centric and website-centric, and process-based classification).

The concept of e-commerce (Figure 1) is similar to the solar system, where the e-commerce is the central star and it must include on its orbit all the other stars. Once one of the surrounding stars gets lost from its orbit the whole system's stability can be checkmated. Whether for lack of credibility, poor branding concept or simply due to a poor visibility, any failure on one of the factors implies that the project may not work properly and there are plenty of online stores that just do not sell. Next, each of the proposed critical success factors will be analyzed separately.

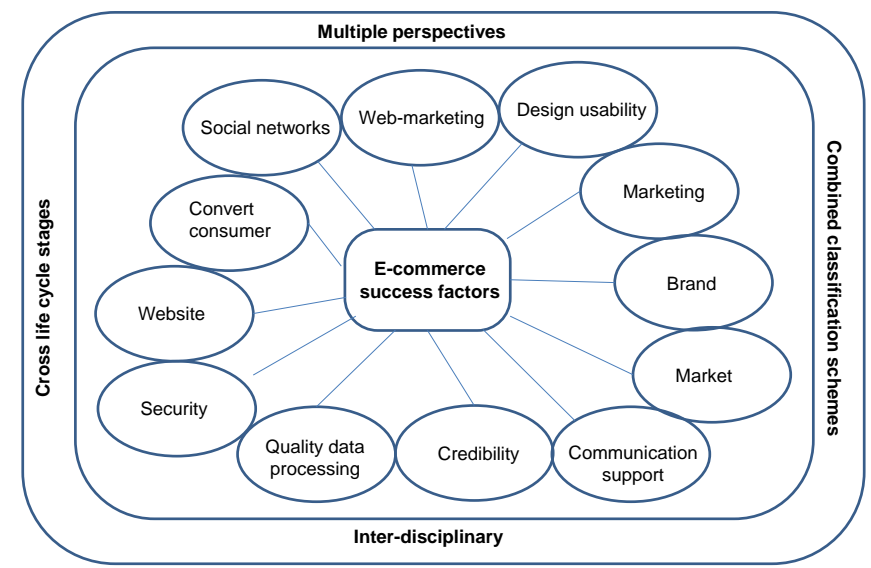

Figure 1. An integrated conceptual model of critical success factors for ecommerce.

\section{A. Social Networks}

Social networks have changed the way people communicate; it was like reinventing something we did naturally, with a slower speed. The initial idea was aimed at friends to join on a virtual network where they could communicate about everyday's life. This phenomenon has exceeded expectations and inevitably began to move towards the business world. If customers are concentrated on a particular community, nothing is more natural than participating on it.

Nowadays, all major brands present themselves within this environment, trying to reach a huge market with a multiplying growing effect [25]. Applying the phenomenon of social networks to e-commerce, has the additional advantage of reaching people that are already regular users of the Internet, and to capture their attention to new products and services requires a good communication and marketing strategies to be implemented. Thus, one can gain customers through these communication engines, enhancing the target market.

\section{B. Web-marketing}

Although a segment of the Marketing, the Web- Marketing deserves special mention, for conceiving a fantastic store, in terms of design and image, may seem to be good enough for becoming very successful. However, imagine how disastrous it would be if no one would pass on the street where the shop is located and the same may happen regarding online stores (http://www.acepi.pt).

Search engines provide the initial dialogue between consumers and online stores; therefore a good positioning or ranking of a website is of utmost importance. Search engines, like Google, also have tools to measure how many times certain words are searched and analyse all statistical data about the number of visitors about a given online store. Hence, improving search strategies is another important success factor.

There are several ways for enabling good rankings of websites within searching engines, which turns out to be even more important when a website includes sponsored links. The 
best way to attract potential customers is to accurately know the market where it operates, so that the whole effort is focused in favour of the business [25].

\section{Design Usability}

In an on-line shop the customer interface occurs via the website, therefore, their expectations have to be met as they easily may move away to the competition.

One crucial issue on the design of any information system is the usability of the user's interface. According to ISO 9241 Part 11 (1998) usability is defined as the effectiveness, efficiency and satisfaction with which specific users achieve goals in particular environments. These definitions relate directly with 3 questions: How can users perform their tasks? What resources must users spend to achieve a given outcome (e.g., time, effort)? How well do users like the application?

Besides the economical costs (i.e. a system that is hard to understand is also hard to sell, and may involve many expensive problems in its life cycle), the lack of care about users needs can lead to solutions that tend to cause errors or that provide users with inadequate information. For e-commerce, this is particularly harmful because it implies losing customers [26].

Usability is an essential critical success factor to take in consideration in the design of websites because it is not a single, one-dimensional property of a user interface. Usability has multiple components and is traditionally associated with five usability attributes: learnability, efficiency, memorability, errors, and satisfaction [27].

\section{Marketing}

Using an appropriate marketing strategy along with an improved business offered and other non-technological areas are crucial multidisciplinary requirements for the success of ecommerce. Moreover, once a brand is defined - and this applies to any product - it needs to be recognized as a reference. A wellstructured marketing plan, with a well-defined line and an innovative and credible image are essential success factors for promoting any brand or product [1].

From videos and images up to workshops and international conferences, it is worth using all channels of communication to solidify the brand on the market. Thus, it becomes a necessity to innovate and to re-invent the way we present ourselves to the world [28].

"To take a step ahead and anticipate the future may be a mirage, however, with marketing the mirage becomes less unfocused." Miguel Floriano

\section{E. Brand}

Nowadays, the world of brands moves millions, as increasingly more companies look for convincing brands, to better affirm themselves among competitors [25]. In ecommerce the paradigm does not change, to buy online, you need something to push you to finalize your purchase. It is not enough to think that a brand is just a cute name or a futuristic logo, the whole communication with the surroundings has to be well thought, and the care and concern about the customers need to be visible in order to enable to construct a loyalty based relation with them [25].
The concept of a brand has to have the objective to be a precise way to reach the clients and establish a collaborative interaction with them by enabling integration of different areas. Impact, desire and trust are the ingredients that may enable a common brand to become a benchmark worldwide. If the main purpose of the brand is not describable by a few words, it is most probably not well designed.

\section{F. Market}

Knowing our business can help to know, "where we are" and "where we want to go" [1]. Measuring performance at each step of business allows adjusting measures to consider and values to obtain, through a sustained growth. This measurement is only possible if there are predefined and measurable goals for market trends. Therefore, it is necessary to know if it is a marketplace of thousands, millions or billions.

The more information available the better our position will be to support good decision making strategies. Understanding the marketplace is the first step, setting goals is the second one and nothing serves the former if there is no continuous analysis of results obtained.

\section{G. Communication Support}

When buying on an online store, its success is only possible if there is a satisfactory level of communication support along the entire supply chain, which must be synchronized and integrated [29]. A climate of trust and sharing must prevail, so that the whole quality of the system is reflected on the final consumer [30].

If the manufacturer and all intermediaries are not sharing the same values, the whole communication within the supply chain may be compromised and the concept of a successful online store will most probably fall. Imagine how disastrous it would be having a well-designed online store, with a powerful marketing and numerous customers and the delivery due dates of the products were constantly being violated [31].

Only the skilled ones can be a part of the successful communication and supply chain, for each one, on its "core business", to provide its best possible contribution, always focused on reaching integration and common objectives and customer satisfaction.

The clients and their satisfaction must be constant concerns of any company aspiring to reach a sustainable growth [24]. Moreover, in a medium like the internet, additional concerns about the fact that many users still do not feel comfortable buying products they cannot physically see, have to be kept on mind. One central concern of a consumer is about knowing if the website provides support to clarify questions about products or services; and, in particular, issues related to product returns or simply about how to get more direct information about the provided products and/or services. With the growth of the Internet there are also many online shops whose quality standards do not meet customer requirements, installing uncertainty on the marketplace.

It is of utmost importance to provide a full service support, before, during and after purchase. This way the clients feel supported and understood and not afraid to repeat the experience and buy through the same website. 
The word "guarantee" frightens many entrepreneurs; however, this paradigm must change as people buy more if they feel fully supported and "safe" and in the majority of online stores the rates about product returns are quite low [24].

\section{H. Credibility}

Regarding marketing strategies to incentivize anyone to buy through an online store, there are still many entrepreneurs targeting cost reduction instead of investing on that direction to enrich online stores' credibility. A shop with an "amateur" aspect easily distracts consumers that are more already suspicious about online shopping.

A good call centre, setting up a company with physical office, a registered trademark and the overall design and functionality of the website should not be jeopardized due to a low budget. Moreover, being professional and combining all these details will help strengthen the credibility of the store. Another key factor consists on joining forces and partnering with credible companies [29].

\section{Quality Data Processing}

The features of the website should be working perfectly; no bugs or links that do not work are allowable. When usability is jeopardized and something stops working and confuses the user this may compromise the quality of the whole website and the underlying information system project, along with the correct functioning of the communication channels and the underlying operation of the supply chain, which is essential to gain the users confidence.

Moreover, the quality of the delivered product and/or service can be compromised while lacking quality data processing, therefore, it is of upmost importance to ensure quality data processing [32].

\section{J. Security}

With the exponential growth of the Internet shopping, security has been the major concern of users. However, increasingly more money transactions take place and the systems are becoming considerably safer. Selecting safe payment methods and be at the forefront of information technology about security issues, is a competitive advantage on on-line selling. Thus, if the client is aware about the on-line shop concerns to ensure secure payment transactions, the brighter the image of trust and responsibility will be passed to potential clients.

Although the world is aware that issues about security breaches continue to rise on data computing and Internet transactions, and as even the most protected systems are transposable, we must maintain the dedication to guarantee purchases as much secure as possible. Moreover, to attract online customers e-commerce business should understand the customers' real wishes and expectations and what payment methods each type of segment of users does prefer. Each marketplace has its peculiarities and consumers tend to create common purchasing habits with which they feel more comfortable, e.g. "to use the online shopping cart" [26].

\section{K. Website}

The website is a showcase of the online store, which has to take into account to whom it should attract attention, as its mere existence does not mean its success. The whole construction of the website must be developed by a multidisciplinary team because there are several areas that will be involved for achieving the final product with the intended image and functionality. For example: the programmer may build the website quite clearly, without any bugs or technical problems, but if the designer does not provide an efficient interface it probably will fail [33].

Therefore, all those multidisciplinary areas should be taken in consideration on the creation of any website, so that each area can provide an important contribution to the final result of the website Any successful e-commerce website must be robust, complete, appealing and balanced to ensure passing an image of a serious and credible company, without any tendentious reflection just about a particular area or concern.

\section{Convert Consumer}

Once achieved the complete flow of the market to the online shop, there is still another important but less explored subject, which consists on being able to convert a visitor into a customer [34].

With the tools available on the market it is possible to analyse many details about visits to a website. From the time each user wastes browsing, up to the number of visitors per day, broken down by country and other indicators, many different kind of analysis are possible.

When the number of visits to a website is big and the sales have not risen, something must be done to reverse potential customer's bad attention. Issues related to websites usability, communication and marketing problems must be completely revised to ensure e-commerce success.

\section{CONCLUSION}

Knowing the necessary ingredients for success in ecommerce, is crucial to build a highly profitable and consistent e-commerce business. Building an online shop based on a fully integrated model (MPCSF) regarding the most important critical success factors, will enable a successful on-line business and transmit confidence to potential on-line clients.

Therefore, it is of upmost importance not to distract customers, while compromising the balance of a whole website. There is still plenty of room for improvement in the market of online shops, as more and more people choose this kind of shopping, which enables entrepreneurs to get closer to its market, while presenting an appropriate solution for their clients' expectations. Moreover, it is necessary to pay attention to aspects for enabling a good e-commerce practice. Often those aspects are under estimated due to lack of analysis and investigation regarding a set of proposed success factors described through this work.

The proposed critical success factors incorporated in the MPCSF model in this paper are not only related to the website, its design and usability, but also with: the brand; the marketing and web-marketing strategies; social networks reaching; 
concerns about the whole supply chain integration; concerns regarding consumers conversion, communication and support; looking at quality data processing and secure payment methods; and enabling a favourable image for reaching on-line shop credibility. Compared with existing conceptual models for ecommerce success factors in the literature, there are four key contributions of the MPCSF, including:

If defines new critical success factors such as converting customers and credibility; (b) the MPCSF model intends to include stages beyond the existing online shopping life cycle, i.e. it considers not only the information phase, agreement phase, transaction phase and delivery phase, but also the pre- and aftersale phases; (c) as the model name suggests, the model incorporates the critical success factors from multiple perspectives - technology, social and ethical perspective; (d) the model integrates knowledge from multiple disciplines such as Engineering, Science and Technology, and Business Management. Therefore, the proposed MPCSF model can provide a more comprehensive understanding of on-line shopping in order to achieve business success.

In addition it has been identified that a more professional attitude is needed, as all these factors are of the biggest importance for ensuring the difference between a modest online store and an online empire. Future work would refine the critical success factors already identified in the MPCSF model and try to better understand the relationships between the success factors. Future research will also extend the evaluation of the MPCSF model to a set of websites' design and implementations in practice.

\section{ACKNOWLEDGMENT}

This work has been supported by COMPETE: POCI-01-0145FEDER-007043 and FCT - The Foundation for Science and Technology within the Project Scope: UID/CEC/00319/2013.

\section{REFERENCES}

[1] Alturas, B., Conceição, M., Brites, R., 2006. Direct Selling: Finding Consumer Segments. In: Proceedings of the EIRASS International Conference, 9th-12th July, Budapest, Hungary.

[2] Ascensão, C. P., 2011. Google Marketing: A arma mais poderosa para atingir os seus clientes. 1st Edition (in Portuguese)

[3] Atchariyachanich, K., Okada, H. and Sonehara, N., 2008. Critical success factors of Internet shopping: the case of Japan. In Proceedings of the 4th International Conference on E-business and Telecommunication Networks. Book series "Communications in Computer and Information Science" (editors: Filipe J and Obaidat MS). Volume 23, pages 98-109.

[4] Bandyopadhyay, N., 2010. A conceptual understanding of the impact of market space on the four P's of marketing. In: Int. J. Electronic Customer Relationship Management, Vol. 4, No. 1 Inderscience Enterprises Ltd.

[5] Becerra, E. P. and Korgaonkar, P. K. 2011, Effects of trust beliefs on consumers' online intentions, European Journal of Marketing 45(6):936-962.

[6] Brege, S., Brehmer, P., Rehme, J., 2008. Managing supplier relations with balanced scorecard. In: Int. J. Knowledge Management Studies, Vol. 2, No. 1. Inderscience Enterprises Ltd.

[7] Burgess, S., 2008. Determining website content for small businesses: assisting the planning of owner/managers. In: Int. J. Knowledge Management Studies, Vol. 2, No. 1. Inderscience Enterprises Ltd.

[8] Cebi, S., 2013. Determining importance degrees of website design parameters based on interactions an dtypes of websites. Decision Support Systems 54: 1030-1043.
[9] Chen, Y.T. and Chou, T.Y., 2012. Exploring the continuance intentions of consumers for B2C online shopping: perspectives of fairness and trust. Online Information Review 36(1): 104-125.

[10] Clements, M. D. J., Dean, D. L., Cohen, D. A., 2010. Supplier selected relationships choosing friends, over family. Int. J. Manufacturing Technology and Management, Vol. 19, Nos. 1/2. Inderscience Enterprises Ltd.

[11] Duncan, K., 2011. Marketing Greatest Hits. First Edition.

[12] Fang, Y.H., Chiu, C.M., \& Wang, E.T.G. 2011, Understanding customers satisfaction and repurchase intentions: an integration of IS success model, trust, and justice. Internet Research 21(4):479-503.

[13] ISO 9241-11 (1998) Ergonomic requirements for office work with visual display terminals (VDTs) http://www.usabilitypartners.se/usability/standards.shtml.

[14] Joma, S.I., 2009. Research on e-commerce trends and development to enhance online customer satisfaction in China. In proceedings of the 8th Wuhan Interntaional Conference on E-business (editor: Duserick, F.G.). volumes 1-3, pages 94-99. 30th31st May 2009, Wuhan, China.

[15] Kawasaki, G., 2004. The Art of the Start.

[16] Lee, Y. and Kozar, K.A., 2006. Investigating the effect of website quality on ebusiness success: an Analytic Hierarchical Process approach. Decision Support Systems 42: 1383-1401.

[17] Lee, G.G. and Lin, H.F., 2005. Customer percpetions of e-service quality in online shopping. International Journal of Retail \& Distribution Management 33(2): 161176

[18] Machado, A. T. M., 2011. Usability: Impact on E-commerce. PhD Thesis, Technical University of Lisbon.

[19] Ngai, E.W.T., 2003. Selection of websites for online advertising using the Analytic Hierarchical Process. Information and Magement 40: 233-242.

[20] Nielsen, J. (1993) Usability Engineering. Academic Press.

[21] Olson, J.R. and Boyer, K.K., 2005. Internet ticketing in a not-for-profit service organisation: building customer loyalty. International Journal of Operations and Production Management 25(1): 74-92.

[22] O'Reilly, K. and Marx, S. 2011, How young technical consumers assess online WOM credibility, Qualitative Market Research: An International Journal 14(4):330359

[23] Parasuraman, A., Zeithaml, V.A. and Berry, L.L., 1988. SERVQUAL: a multiple item scale for measuring customer perceptions of service quality. Journal of Retailing 64(1): 12-40.

[24] Shahabuddin, S., 2011. Supply Chain Management and its effect on company's performance. In: Int. J. Logistics Systems and Management, Vol. 8, No. 1. Inderscience Enterprises Ltd, USA

[25] Torkazadeh, G. and Dhillon, G., 2002. Measuring factors that influence the suces of Internet commerce. Information Systems Research 13(2): 187-204

[26] Suntornpithug, N., Todorovic, Sherrell, D. L.Z. W., 2010. Revisiting the concept of person interactivity through social psychology and social telepresence theory. In: Int. J. Electronic Business, Vol. 8, No. 1. Inderscience Enterprises Ltd.

[27] Thorleuchter, D., and van de Poel, D., 2012. Predicting e-commerce company success by mining the text of its publicly-accessible website. Expert Systems with Applications 39: 13026-13034.

[28] Tsai, M.T., Cheng, N.C. and Chen, K.S., 2011. Understanding online group buying intention: the roles of sense of virtual community and technology acceptance factors. Total Quality Management and Business Excellence 22(10): 1091-1104.

[29] Wolfinbarger, M. and Gilly, M.C., 2003. eTailQ: dimensionlising, measuring and predicting etail quality. Journal of Retailing 79: 183-198.

[30] Wu, Y.L., Tao, Y.H., and Wang, T.C., 2007. Critical success factors for online C2C auction websites - a consumer's perspective. In Proceedings of the 6th WSEAS International Conference on Applied Computer Science. Book series "Electrical and Computer Engineering". Pages: 54-59.

[31] Yuen, S. S. M., 2010. Development of electronic marketplace for collaborative supply chain: a conceptual framework. In: Int. J. Enterprise Network Management, Vol. 4, No. 1. Inderscience Enterprises Ltd.

[32] O'Brien, T. (2015), Accounting' for Data Quality in Enterprise Systems CENTERIS/ProjMAN / HCist 2015, Vol. 64, 442-449.

[33] Schubert, P., 2003. Extended web assessment method(EWAM): evaluation of electronic commerce applications from the customer's viewpoint. International Journal of Electronic Commerce 7: 51-81

[34] Tu, H. J., Yen, W. C., Hou, J. J., 2010. Measuring the operating efficiency of internet channels with DEA. In: Int. J. Logistics Economics and Globalisation, Vol. 2, No. 2. Inderscience Enterprises Ltd. 